\section{ATTEMPTED SUICIDE IN OLD AGE}

\author{
BY
}

I. R. C. BATCHELOR, M.B., M.R.C.P.Ed., D.P.M. Deputy Physician-Superintendent, Royal Edinburgh Hospital for Mental and Nervous Disorders; Lecturer in Psychiatry, University of Edinburgh

AND

MARGARET B. NAPIER, A.M.I.A.

Senior Psychiatric Social Worker, Royal Edinburgh Hospital for Mental and Nervous Disorders

Suicide and the mental disorders of old people are two of the foremost social and psychiatric problems of today. Though the incidence and types of mental disorder occurring in old people have recently attracted much attention, and the rise of the suicide rate with advancing age has long been recognized, few clinical studies of suicide or suicidal attempts in this age group of the population have been reported. This is the more surprising since, as the proportion of old people in the community rises, the suicide rate may for that reason also rise. It is striking, for example, to find in a recent authoritative study of the mental disorders in later life (Kaplan, 1945) only brief reference to suicide, and no elaboration of its clinical aspects.

Gruhle (1941) is often quoted in an opinion which minimizes the importance of psychoses in the genesis of suicidal acts in this age group and emphasizes, as motives, morbid reactions to physical illness and mental incapacity, idleness, boredom, loneliness, and inadaptability in changed circumstances.

Swinscow (1951) in a valuable statistical investigation has come to the conclusion that "suicide in the last 50 years has increasingly become a disorder of elderly people," and has suggested that, " as the present century has advanced, the old may have found their environment more hostile than the young."

Kiørboe (1951) has made a study of 14 old people who committed and 21 who attempted suicide. His condensed findings cannot be abstracted briefly. All his cases were residents in an institution, and his sample is therefore not representative of the community at risk. His conclusions differ materially from those of this paper -for example, he reported in his group a high incidence of syphilis, and found alcoholism to be an important factor and loneliness rare as a motive for suicide.

Roth and Morrissey (1952), from a study of 150 patients over the age of 60 admitted to a mental hospital and a review of the literature, suggest a special association between old age and depressive illness, and support their opinion of the importance of the affective psychoses in this age group by reference to suicide rates. They report that only 12 of their 150 patients had made attempts at suicide, and that each of these was suffering from an endogenous depression. They are critical of Gruhle's opinions, and state that "it is not argued that social factors play no part, but that it is through their role in the precipitation of depressive psychoses that they contribute to the causation of suicide in the old." It seems possible, however, that the factors noted by Gruhle may act not merely as precipitants of depressive psychoses but more intimately in affecting their course and outcome.

There is obviously a need for further studies. Social and psychiatric data must be accumulated, from a sufficient number of cases, at different centres.

\section{General Characteristics of the Cases}

In a series of 200 consecutive cases of attempted suicide admitted to a general hospital in the years 1950-2 and personally observed, $40(20 \%)$ were aged 60 years or over. These 40 cases have been studied in detail. The sample is small, but it is likely that it is reasonably representative of an urban population. The large majority of all suicidal attempts occurring in the city of Edinburgh are admitted to this hospital: suicidal attempts in old people usually demand active surgical and medical treatment, and there is naturally a great reluctance to commit an old person directly, as an emergency, to a mental hospital.

The sex, ages, and marital state of these 40 people are detailed in Table $\mathbf{I}$.

TABLE I

\begin{tabular}{|c|c|c|c|c|c|c|c|}
\hline Age Group & Male & Female & Total & Marital State & Male & Female & Total \\
\hline 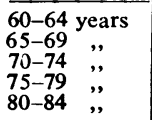 & $\begin{array}{r}5 \\
5 \\
4 \\
2\end{array}$ & $\begin{array}{r}4 \\
11 \\
6 \\
2 \\
1\end{array}$ & $\begin{array}{r}99 \\
16 \\
10 \\
2 \\
3\end{array}$ & $\begin{array}{l}\text { Single } . . \\
\text { Married . } \\
\text { Widow(er) } \\
\text { Separated .. } \\
\text { Divorced ... }\end{array}$ & $\begin{array}{r}3 \\
7 \\
4 \\
2 \\
-\end{array}$ & $\begin{array}{r}10 \\
3 \\
10 \\
1 \\
\end{array}$ & $\begin{array}{r}13 \\
10 \\
14 \\
3 \\
-\end{array}$ \\
\hline Total .. & 16 & 24 & 40 & Total & 16 & 24 & 40 \\
\hline
\end{tabular}

\section{Family Histories}

In $26(65 \%)$ of the cases there was a family history of psychiatric abnormalities, which were manifested in 54 of their relatives ; $7(17 \%)$ of the cases gave a family history of suicide, seven of their relatives having attempted suicide, five successfully. In $14(35 \%)$ cases a history of mental illness in first-degree relatives was obtained. In 12 of these 14, affected relatives had suffered from severe depressive breakdowns: in 6 of the 12 the history was indubitably of manic-depressive psychoses.

\section{Previous Personal Histories}

One-half of this group of people (male 11, female 9) had experienced a "broken home" in their childhood. This high proportion corresponds to that found in a large series of cases of attempted suicide of various ages (Batchelor and Napier, 1953).

More than one-half of the cases (male 9, female 13) had been mentally ill before the present breakdown. Less than one-quarter (male 6, female 3) had previously received psychiatric treatment. The large majority of the previous illnesses had been depressive in character.

Seven individuals (male 5, female 2) had made a previous suicidal attempt. Three of these attempts occurred in an earlier phase of the present illness.

One-quarter of the group were considered to have adequate personalities. The remaining three-quarters seemed vulnerable. Most common factors were a morbid sensitivity and shy seclusiveness which had developed in some instances into jealousy, suspicion, and ideas of reference; and anxious, timid, obsessional dispositions with a tendency to hypochondriasis. A number showed undue dependency of long standing, and passive homosexual trends. The majority had restricted interests.

The intelligences of the group seemed to parallel those of an average sample of the population of the same age.

The great majority of these people had satisfactory work records; but their limiting personality traits, in the cases where frank failures in social adaptation had not occurred, had led usually to no better than fragile adjustments. Social adaptation had been defective in one-half of all the cases. Most of these people had had few friends: self-centred and prickly, they were disposed to loneliness. Only 7 (male 6, female 1) had a present affiliation to any organized nonreligious group. Four of these seven individuals, all men, were members of clubs for old people.

Statistical researches seem to show that religious beliefs play some part in determining the incidence of suicide. Nothing definite in this direction emerged from the present investigation, so the data may be stated briefly. Of the group, 38 were Protestants (one British Israelite and one 
Plymouth Brother included); 2 were Roman Catholics. Almost all expressed a belief in a personal God, while none denied His existence. The majority also believed in some sort of immortality or after-life ; but 6 individuals ( 5 men) stated frankly their disbelief. Only 12 of the Protestants ( 9 women) were church-going; one of the Catholics had lapsed. These older people were on the whole more religious than younger suicidal individuals who were examined. But no evidence was found that their religious beliefs had played any significant part in hindering their suicidal attempts: not one of these people had consulted a minister in his perplexity or was inhibited by fear of punishment beyond the grave.

One-quarter of the group stated that they did not know that attempted suicide was an offence against the law ; while only those whose previous attempts had brought them to police notice knew what precise action the law might take. No evidence was found to show that legal sanctions had acted as a deterrent.

\section{Social Data}

Table II gives an analysis of the social conditions of the group. One-quarter had suffered a fall in social status over their lives, which could probably be correlated with their personality defects. Only one individual had suffered any great change (decline) in social status over the past twelve months. Only three had experienced a significant change in their living conditions in the past twelve months. Apart from the three living a communal life in lodging-house or hostel, one individual suffered from overcrowding and three others lacked privacy at home.

\section{TABLE II}

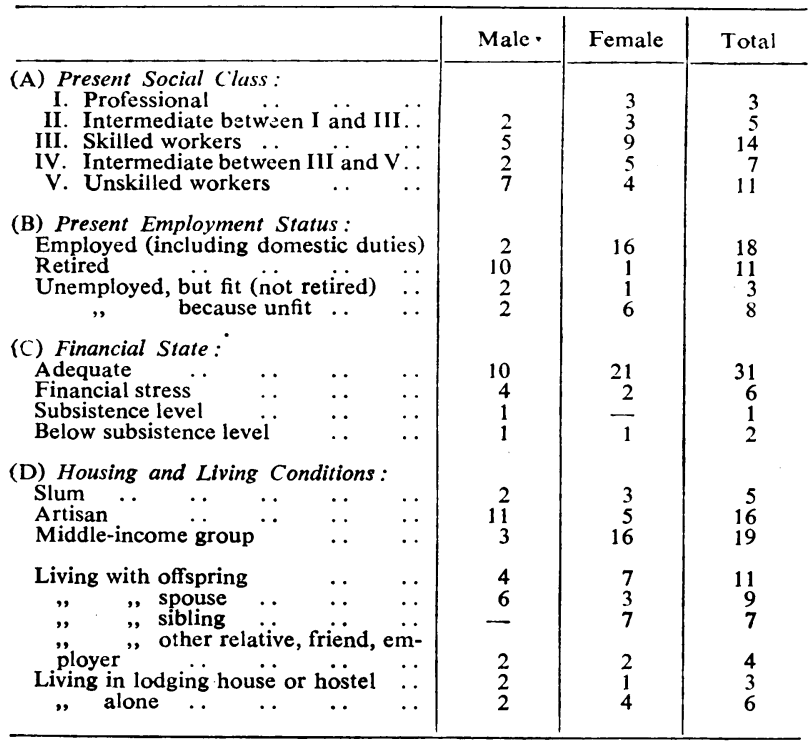

(E) Social Circulation and Mobility.-Of the group 38 were Scottish ; 12 were rural bred ; the majority had spent many years in Edinburgh. In the past twelve months only 5 had changed the locality they lived in, and all these moves were local ones in the city. As one might expect, social mobility was not high in this group: old people prefer to be stationary.

(F) Group Membership.-Details of religious and other group affiliations have been given under the heading of "Previous Personal Histories."

\section{Psychiatric Diagnoses and Symptoms}

Cases of attempted suicide in this age group are more easily classified than those occurring in people in the first half of life. The persons here are usually definitely mentally ill: at least two-thirds are certifiable as insane, and the personalities of the majority are clearly involved to a psychotic extent.
In younger age groups a heterogeneous collection of reaction types is found among cases of attempted suicide; and there is a considerable proportion of persons suffering from psychopathic states and of temperamentally unstäble people allied to these in their reactions, whose precise psychiatric classification is difficult and debatable. But, in old people, clear-cut depressive states comprise the setting in which the great majority ( $80 \%$ in this series) of suicidal attempts occur.

About one-half of the cases of depression in this series were first attacks (Table III). Ten patients had suffered from one previous attack of depression, three from two, two from three, one from four, and one from more than four previous attacks. Only one of these 17 patients had previously

TABLE III

\begin{tabular}{|c|c|c|c|c|}
\hline & & Male & Female & Total \\
\hline 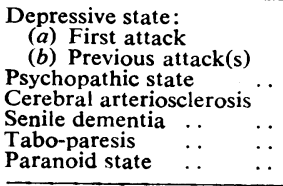 & $\begin{array}{l}. \\
\cdots \\
\cdots \\
\cdots \\
\cdots \\
\cdots\end{array}$ & $\begin{array}{l}7 \\
7 \\
2 \\
2 \\
= \\
=\end{array}$ & $\begin{array}{c}8 \\
10\}_{1} 18 \\
1 \\
2 \\
1 \\
1 \\
1\end{array}$ & $\left.\begin{array}{c}15 \\
17\end{array}\right\}^{32} \begin{array}{c}32 \\
2 \\
1 \\
1 \\
1\end{array}$ \\
\hline Total .. & $\ldots$ & 16 & 24 & 40 \\
\hline
\end{tabular}

attempted suicide. This suggests that the recurrence of a depressive reaction in old age tends to be less well tolerated than earlier attacks: understandably so, since the resilience of the old person is impaired, relapse has added its quota of disappointment, and hope for the future is less native.

Only four individuals $(10 \%)$ suffered from organic reaction types. In each of them the dementing process had not advanced far. These findings are in accordance with expectation, since retention of affect and volition are prerequisites for the genesis of a suicidal act. The depressive affect was prominent also in each of these four cases: one had had a depressive illness, and another had attempted suicide, some years previously.

The symptoms which precede suicidal attempts in old people are symptoms which frequently precede suicidal attempts at other ages, and are the common features also of depressive states which may not proceed to suicide. Depression and insomnia are almost always present. The depression is usually accompanied by anxiety and agitation; there is usually little or no retardation, and the depression may even be masked by a smiling exterior. Insomnia is usually persistent and accompanied by great concern: "It was the want of sleep that was troubling me"; "I haven't slept for four months"-are typical protestations.

Loss of appetite and hypochondriacal complaints about the alimentary tract are common, and the individual may be exclusively preoccupied with them. Complaints of indigestion, flatulence, and intractable constipation may have more or less justification owing to the decreased physiological efficiency of the old person's body, but they often become morbidly dominating and have delusional force: "It's as if I was going to burst "; "I can't expel anything." Such hypochondriacal delusions may be accompanied by other nihilistic delusions-for example, of poverty. Ideas of reference are not uncommon, and a few cases had unsystematized paranoid delusions.

Feelings of weight upon and tension in the head, and head noises, are commonly the bases of fears of insanity. The patient may complain of a feeling of something about to snap in his head, or the feelings may be expressed in more bizarre terms: "It is as if my brains were turning upside down"; "Whiles you'd think there was cold water in it [head]." Only one individual attempted suicide at the command of auditory hallucinations.

A few patients who were fully orientated complained of being " mixed" or " muddled up.". Three others of those suffering from depressions were transiently confused (for a few days) after their suicidal attempts and disorientated in time and place: in at least one of these cases the confusion 
had also shortly preceded the suicidal attempt. In none of these cases was there evidence of drug intoxication or vitamin deficiency, nor, either at the time or later, were there symptoms of cerebral arteriosclerosis. None of them had an amnesia for the suicidal act. It seems possible that the intense, agitated preoccupation with the wish for death had caused a temporary clouding of consciousness, with neglect of the material environment. The term "catastrophic reaction" appears particularly applicable. The confusion in these cases cleared, to unmask a profound depression and intact faculties.

Indications that the inner tension was becoming intolerable to the individual were commonly present before the self-injury was inflicted. Twelve patients $(6 \mathrm{men}$ and 6 women) made direct suicidal threats in the present illness ; 6 other women made suicidal threats by implication.

\section{Physical State}

The physical condition was unsatisfactory in $24(60 \%)$ of the cases: 8 individuals were suffering from cardiovascular disease, 5 were disabled by arthritis, 4 had organic diseases of the nervous system, 3 affections of the alimentary system, 2 of the respiratory. One woman was suffering from mild bromide intoxication.

Serious defects in vision and hearing were found in 4 cases. Malnutrition and loss of weight were common; but in no case was malnutrition accompanied by clinical evidence of vitamin deficiency. Fatigue was almost constantly present.

\section{The Suicidal Attempt}

Old people seem to show a greater preference for active methods of suicide than do younger people. They can rarely give an adequate reason for their choice: the usual reply to questioning about this is, "I don't know." The figures given below show, however, that more than one-half of this series chose poisoning. In this age group, as in others, availability of method plays some part. It is interesting to note that all of Kiørboe's institutional patients used violent methods in their attempts.

Impulsive suicidal attempts in old people are much less common than in younger age groups. Less than one-quarter of the attempts in this series seemed to have been impulsive. More than one-quarter of them had been contemplated for weeks or months.

Four of the poisonings were multiple; these have been listed under the main toxic agent (Table IV). One man cut both throat and wrist.

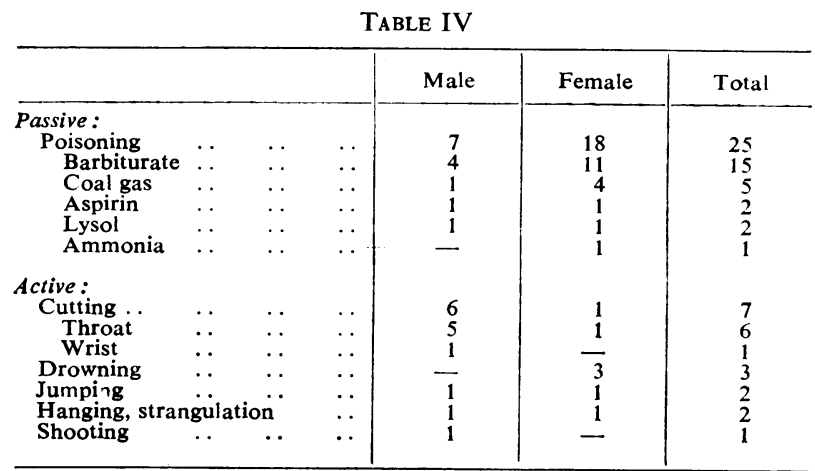

The attitude of the patients after their suicidal attempts is shown in Table V.

TABLE V

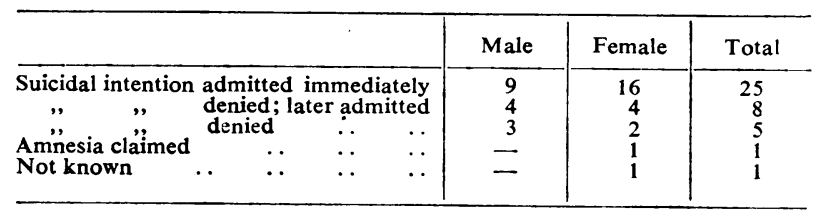

There is rarely any doubt that the suicidal attempt of an old person has been a genuine one. Those who deny their suicidal intentions usually admit to having had feelings of hopelessness. The denial may be paradoxical: one man who had come into hospital asking to be kept safe from his suicidal urges, later, when admitted after taking 100 aspirins, denied his suicidal intentions; a woman said, "I have a confession to make to you, I didn't attempt to take my life."

Of the 40 cases, $22(55 \%)$ had to be admitted for further treatment to a mental hospital-almost twice the percentage immediately requiring such treatment in a series of cases of suicidal attempts in adults of all ages.

\section{Precipitating Factors and Motives}

The diagnosis of an abnormal type of mental reaction in the individual concerned is not a sufficient explanation of a suicidal attempt. While it is probably true that more suicidal acts in old age can be more nearly explained in terms of mental illness than is the case in younger age groups, the question immediately arises: Why is it the minority of the sufferers from these illnesses who are driven to suicide? There is no mental illness, in any age group, the majority of whose victims make suicidal attempts. A case history may be briefly quoted here.

A retired public servant aged 72 , none of whose near relatives had been mentally affected and who had never himself previously had a nervous illness, whose personality had been robust and work record exemplary, was bereaved of his spouse. Shortly afterwards his only son married and brought a young and aggressive wife into the house. In this setting the old man became deeply depressed in his spirits, took alcohol in excess for the first time in his life, committed, while sober, his first police offence by shoplifting, and, when partly under the influence of alcohol, made a determined suicidal attempt. There was no organic mental deterioration.

The depressive reaction in this case apparently released three distinct kinds of abnormal conduct. Even if we suppose it to have been the essential condition for the development of the deviant behaviour, the different deviations cannot conclusively be given the same, even if it is an attractively simple, explanation. We cannot be content with the finding that the depressive psychosis has been the main item in the aetiology of this suicidal act.

In old people as in all other age groups, the aetiology of suicide and suicidal attempts is multiple. So far as we know. there are no aetiological factors, either personal or social. which are peculiar to any one age group. But in the case of old people certain personal factors are more commonly, and others less commonly, encountered than they are at other ages. Among suicidal old people feelings of loneliness and of increasing physical incapacity are very often found: dramatic gestures, demonstrations of omnipotence, and reactions of escape from social embarrassments are uncommon, and intoxication is less often a complication.

Loneliness.-Feelings of loneliness, of being a burden on others, or of being unwanted, found in 23 of the 40 cases, were the commonest psychological precursors of suicidal attempts in this series. Frequently the old person states that it was a feeling of estrangement which most powerfully prompted his act: "I felt as if nobody wanted me"; "I just stay myself, I feel lonely"; "I felt I was keeping my daughter back." The same sentiments are commonly expressed in suicide notes.

Social integration is a concept which is difficult to define, and which cannot be expressed satisfactorily merely by stating the living conditions. It is obvious that an individual who is living alone may not be lonely; while a member of a family group may feel isolated. Social integration exists where there is a reciprocal sympathy between the individual and his social environment: loneliness is a sensitive indicator of its deficiency. The domestic background of the cases of this series in which loneliness seemed an important factor is interesting and, though the numbers which may be quoted are too small to be dependable, they are probably significant. Loneliness was a factor in 10 of 11 of those 
living with offspring, in 8 of 8 living alone or in a lodginghouse, in 3 of 7 living with a sibling, and 0 out of 9 living with a spouse.

It is recognized that the incidence of suicide in an urban area may be correlated with the percentage of those in the community living alone (Cavan, 1928 ; Sainsbury, 1951). The above figures may be held to confirm this to some extent ; but they also emphasize that the old person may be nominally integrated by being a member of a family group and yet feel socially isolated. There is a suggestion in these figures that to be with coevals is for the old person easier than to have to adjust to the pace of life and interests of younger people. And it was clear that, in certain cases, to the loneliness in some measure inseparable from old age itself there had been added the bitter experience of emotional rejection by the children who resentfully were materially supporting and housing the old person.

Physical Incapacity.- This was a major factor in 18 cases. It was not the degree of disability which seemed usually the important element, but the rapidity of its onset or its unexpected nature. The ageing individual, with limited assets, may have to meet abruptly a new and disturbing situation. A fall, producing only bruises and shock, or increased demands upon energy and resourcefulness owing to the illness of a helpmate, may bring the old person to a sudden realization of his frailty. Forced by ill-health to keep to the house or to take temporarily to bed, he may see in this a threat of permanent invalidism and helplessness, and decide that such a future would be intolerable. Many patients after their suicidal attempts reported such reactions: "I was beginning to feel my age"; "I felt I was done"; "Lying in bed for a fortnight upset things ; I was accustomed to a hard life all my days." Physical pain and discomfort strengthened the suicidal urge in 8 cases. Increasing blindness was a leading cause of suicide in one case. Three individuals were severely deaf: though they did not make their deafness a major complaint, it must have contributed to their social isolation.

Fears.-Closely allied to the above and found also in 18 cases, based usually on a misinterpretation of somatic symptoms, are fears of having contracted a fatal physical illness or of becoming insane. The physical illnesses most commonly the foci of phobias were cancer and heart disease ; phobias of tuberculosis and of venereal disease were also encountered. Eight patients feared insanity, and in three of these cases the suicidal act was precipitated by arrangements being made for mental hospital admission. Perhaps the most potent fear of all is the dread which is nameless and unfocused, and from which the patient sometimes comes seeking protection saying that he feels that something terrible, he knows not what, is about to happen.

Identification with a Dead Person.-In suicides of all ages, identification with, or the hope of rejoining, a dead person is a prominent motive: it was found in 11 cases in this series-about the same percentage of cases as in a larger group of adults of all ages (Table VI). In younger people the dead individual most commonly identified with is the mother; in old people it is the spouse.

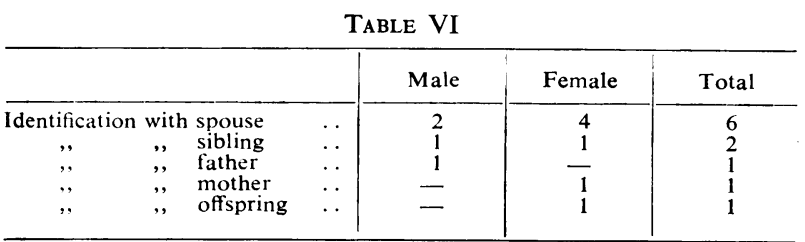

Financial Anxieties.-These played a part in the suicidal attempts of 6 individuals ( 3 men and 3 women).

Hate.-Hatred of another person, an important and striking motive in many of the suicidal attempts of younger people, is a less common element in the suicidal attempts of old people-unless one is to presume its presence in all those who are living with relatives and are to some degree estranged from them. At any rate, if it is commonly present as a motive in old people it is usually less obvious and less intensely focused. Few suicidal attempts in this age group are precipitated by overt quarrels ; and spite, revenge, pique, and jealousy are infrequent motives. Homicidal trends were clearly identified in only four cases. One old man confessed to fears that he might harm the married daughter whom he was living with and who was showing him little affection; another warned his wife not to sleep with him, in case he might strangle her. A widowed woman brandished an axe over her only daughter, who was shortly to get married; and a spinster had obsessional thoughts and impulses towards attacking with a knife her younger and more attractive sister.

Guilt.-This factor, often difficult to assess, was infrequently expressed by these suicidal old people in depressive delusions or in self-reproach. It does not appear to be a major factor in the suicidal attempts of the senium.

Alcohol.-Three men were under the influence of alcohol at the time of their suicidal attempt, but not to the degree that they later had an amnesia for the act. Two men and two women habitually took alcohol in excess; two men and one woman had previously been alcoholic.

Other Factors.-Retirement from work contributed directly to the suicidal attempts of two men; but its more indirect and insidious effects are difficult to gauge. Recent moves of home and changed domestic circumstances precipitated the attempts of two women. The death of friends appeared to be the motive in only one case. Disillusionment is hard to judge: it is part of the senescent attitude to life ; one would not expect it to be of lethal strength.

One is aware, in listing the various motives, that some of them are superficial and derived from the patients' rationalization, and that the explanations advanced are at best partial. Ultimately these morbid acts are discharged at an unconscious level and are the outcome of a tremendous emotional turmoil, of which we discern only some of the effects. We guess at the strength of the despair, and we assume, though we cannot clearly define, the lessened controls.

\section{Discussion}

The state of the old person who attempts suicide reminds us of the vivid words of that Anglo-Saxon elegy, The Wanderer:

" He knows who puts it to the test how cruel a comrade is sorrow for him who has few dear protectors; his is the path of exile, in no wise the twisted gold; a chill body, in no wise the riches of the earth; he thinks of retainers in hall and the receiving of treasure, of how in his youth his goldfriend was kind to him at the feast. The joy has all perished.... Then comes darkness, the night shadow casts gloom, sends from the north fierce hailstorms to the terror of men. Everything is full of hardship in the kingdom of earth; the decree of fate changes the world under the heavens. Here possessions are transient, here friends are transient, here man is transient, here woman is transient; all this firm-set earth becomes empty."

In this age group, as in others, while suicide may appear a sufficiently logical reaction to an intolerable situation, it is in very few instances carried out under the direction of reason unperverted by morbid emotions.

The infirm situation of the old person needs no elaboration here; his vulnerability to disease and death and his relative social inutility are obvious. With a sense of this latter old people may be rather deeply imbued. In certain primitive societies it was conventional, and apparently occasionally obligatory, for old people to commit suicide when on account of their infirmity they had become a burden on the rest of the community. A period of famine was then the usual precipitant of their self-sacrifice. While such crude biological and economic pressures have been more or less lifted from old people in our society, the mechanization, pace, and restless competitiveness of an industrial civilization may equally be inimical to them.

Prone as he is to painful feelings of being a burden to others, it is obviously very necessary for the old person, 
particularly if he is no longer economically useful, to feel loved and wanted. There is much concern about the welfare of old people, but the very fact that their position is receiving such detailed scrutiny indicates that their social status is changing. In their ever-increasing numbers old people are becoming a social problem, and the fear is expressed that they may be becoming a social burden. Old people seem more often now to be falling outside family units. The attitude of our society as a whole seems to be ambivalent. There is a tendency, for example, towards segregating old people - a tendency which is not wholly explicable in terms of the housing shortage; and, while the importance to the old person of continued employment for as long as possible is stressed, arbitrary and traditional ages of retirement are maintained and even embodied in new legislation.

Though, judged by crude material standards (such as their financial state or their housing situation), the old people in this series of cases were in general not badly off, there was evidence that they were subject to environmental stresses, particularly to community attitudes expressed in the behaviour towards themselves of their own relatives, which, though more subtle, were not less wounding. Most of these old people were also temperamentally vulnerable. Many gave a family history or previous personal history of nervous or mental illness ; many had suffered the disabilities of a broken home in childhood; and most of them had defects of personality which had made them prone to reactions of anxiety and insecurity, and to social isolation with its attendant feelings of loneliness. It seems that when a depressive illness develops in such a predisposed individualparticularly when resistance, already lowered by the effects of old age, is still further impaired by physical ill-health, and there is a lack of love due to the loss of a marital partner or rejection by offspring - a reaction of weariness, loneliness, and despair may be set in motion which tends to eventuate in suicide. This is a generalized statement ; but it is doubtful if we have at present enough evidence to be more specific. Each case differs in certain respects; predisposing and precipitating factors vary in the relative intensities of their incidence, and much in every case remains unknown.

It is evident from the above that the known factors which tend to precipitate suicide in old people are the same factors which in general tend to precipitate their mental breakdown. The prophylaxis of suicide in this age group coincides, therefore, with the wider objectives of a programme of mental hygiene, about which fortunately there is now wide theoretical agreement. The promotion of optimum mental health in earlier years; the encouragement of continued occupation for as long as possible and the fostering of other interests ; the maintenance of social integration; the avoidance of undue fatigue; the early and adequate treatment of physical illness and the alleviation of fears about it; the prompt diagnosis and treatment of mental illness, and particularly of depressive reactions; the recognition of the warning in the suicidal talk of the old person: all these items and objectives are of the greatest importance, and in their pursuance a great many agencies and individuals have their parts to play. The problem is far wider than merely a medical one. Suicide is a disease of the community, and the community as a whole has to exert many resources in its self-healing.

\section{Summary}

In a series of 200 consecutive cases of attempted suicide admitted to a general hospital 40 were aged 60 years or over. Detailed social and psychiatric data about these 40 cases are presented.

A family history of psychiatric abnormality was obtained in $65 \%$ and of suicide in $17 \%$ of the cases.

One-half of the group came from "broken homes." More than one-half had previously been mentally ill. Previous suicidal attempts had been made by $17 \%$. Three-quarters had vulnerable personalities, which tended to isolate them socially.
Of the suicidal attempts $80 \%$ occurred in the setting of a depressive state. Evidence suggested that the recurrence of a depressive illness in old age had been less well tolerated than earlier attacks, and that the suicidal attempt of an old person is almost always a genuine one. Less than one-quarter of the attempts had been impulsive.

Significant physical disease was present in $60 \%$ of the cases.

Attention is drawn to the multiplicity of precipitating factors and motives, and stress is laid on the importance of feelings of loneliness and physical incapacity, fear, and identification with a dead person.

Adverse social factors of a material kind were found to be less important than community attitudes, which tend to make the old person feel useless and unwanted.

The importance of the problem of suicide in old people is emphasized, and a relevant mental hygiene programme is outlined.

We are grateful to Professor Sir David K. Henderson for his criticism and advice, and to Dr. J. K. Slater for permission to study these cases in his wards of the Edinburgh Royal Infirmary.

REFERENCES

Batchelor, I. R. C., and Napier, M. B. (1953). Brit. J. Delinq.. 4. 99 Cavan. R. S. (1928). Suicide. University of Chicago Press, Chicago Gruhle, H. (1941). Altersforsch 3. 21.

Kaplan, O. J. (1945). Editor of Mental Disorders in Later Life. Stanford University Press, Stanford, California. Kiørboe. E (1951) J Gerontol. 6,233

Roth. M., and Morrissey, J. D. (1952). J. ment. Sci.. 98 66

Sainsbury, P. (1951). Quoted bv A. Lewis in Edinb. med. J., 58, 227. Swinscow. D. (1951). British Medical Journal, 1, 1417.

\section{WORK AND AGE: STATISTICAL CONSIDERATIONS*}

BY

\author{
W. P. D. LOGAN, M.D., Ph.D. \\ Chief Medical Statistician, General Register Office
}

I propose to deal with four basic considerations regarding the elderly worker : (1) the relative numbers of old and young people in the population ; (2) the proportions of old people still at work; (3) the relative mortality risks to old people in various broad types of employment ; and (4) the amount of time lost on account of sickness.

\section{Population}

It is no longer news to any audience to announce that the proportion of young people in the population of this country is becoming smaller and that the proportion of elderly people is increasing. This situation, which is occurring in most Western countries as well as our own, is the result of a prolonged decline in the birth rate from about 1870 until about 10 years ago, accompanied by a reduction in mortality that began a few years earlier and which is still continuing. The outcome has been an age redistribution of the population, and Fig. 1 shows the changes that have occurred during the past 110 years and also what the situation is likely to be in 1991, as estimated on the basis of some simple and reasonable assumptions about trends of births and deaths during the next few decades. The proportion of the population of working ages, taking these as 15 to 64 years, has increased during the past century, and by 1951 there were 67 people of working age to every 33 people outside this age range-that is, two-thirds of the population in 1951 were aged 15-64. Unfortunately, the ratio of persons

*Read in opening a discussion in the Section of Occupational Health at the Annual Meeting of the British Medical Association Cardiff, 1953. 